\title{
Studi Eksperimental Fuzzy FES Control untuk Pergerakan Knee Joint
}

\author{
Stanley Setiawan, Achmad Arifin, Fauzan Arrofiqi, Aidatunisadina Linazizah Basith dan Mohammad Nuh \\ Teknik Elektro, Fakultas Teknologi Industri, Institut Teknologi Sepuluh Nopember (ITS) \\ Jl. Arief Rahman Hakim, Surabaya 60111 \\ E-mail: arifin@ee.its.ac.id
}

\begin{abstract}
Abstrak-Pada tugas akhir ini telah dikembangkan sebuah perangkat wearable functional electrical stimulation untuk merestorasi gerakan pada knee joint. Perangkat keras dirancang dengan menggunakan sensor accelerometer dan gyroscope yang dapat mengukur posisi dan kemiringan sudut, dan rangkaian electrical stimulator yang dapat menstimulasikan otot untuk melakukan knee extension dan knee flexion. Pada pengujian sistem sensor, dilakukan pengukuran pada model kaki statis yang digerakkan dan didapatkan nilai RMSE pada knee joint sebesar $0.714^{\circ}$. Pada pengujian rangkaian electrical stimulator tegangan maksimum yang dapat dihasilkan sebesar 95 Volt, dengan frekuensi $20 \mathrm{~Hz}$ dan lebar pulsa sebesar $200 \mu \mathrm{S}$. Untuk menguji pada subyek, elektroda ditempatkan pada otot biceps femoris long head untuk melakukan knee flexion dan otot vastus femoris untuk knee extension. Besarnya tegangan pada saat stimulasi knee flexion umumnya lebih besar daripada stimulasi knee extension. Hasil pembacaan sensor pada subyek kemudian akan dijadikan sebagai feedback untuk sistem kendali cycle-to-cycle control yang dikendalikan oleh fuzzy rule based system. Untuk melakukan knee extension, metode yang digunakan adalah multiple input single output (MISO) yang menggunakan nilai error dan desired range sebagai input, sedangkan dalam melakukan knee flexion digunakan single input single output (SISO) yang hanya menggunakan nilai error sebagai input. Keluaran fuzzy system ini adalah $\Delta$ TB sebagai burst duration dari stimulasi yang dihasilkan
\end{abstract}

Kata Kunci-Cycle-to-cycle control, FES, unctional electrical stimulation, Fuzzy, Knee joint

\section{PENDAHULUAN}

$\mathrm{P}$ ENYAKIT seperti stroke dan kelumpuhan ruas tulang belakang (spinal cord injury) pada umumnya menyerang sistem saraf dan dapat menyebabkan degenerasi yang cepat pada otot-otot skeletal yang mengakibatkan paralisis [1]. Pada umumnya, pasien penderita penyakit tersebut mengikuti program fisioterapi yang salah satunya adalah Functional Electrical Stimulation (FES).

Sistem kerja dari FES ini dilakukan dengan memberikan stimulus elektris pada otot skeletal untuk menghasilkan kontraksi. Dengan adanya kontraksi, maka otot akan menghasilkan torsi pada persendian-persendian yang menyebabkan terjadinya gerakan [2]. Pada umumnya, FES yang biasa ditemui di rumah sakit berukuran cukup besar dan diperlukan proses kalibrasi yang panjang sehingga tidak semua orang dapat menggunakannya. Sedangkan, penggunaan FES yang intens dapat memperbaiki mekanisme pemulihan pada anggota tubuh yang distimulus lebih cepat.

FES yang wearable pada umumnya dilengkapi dengan sensor gerakan untuk gait analysis (analisa berjalan) dan juga bagian stimulator. Pada bagian stimulator, FES akan menghasilkan pulsa yang akan menstimulus otot - otot yang telah ditentukan. Sebuah mikrokontroler digunakan untuk membangkitkan pulsa stimulus. Selain mikrokontroler, rangkaian driver juga ditambahkan pada FES agar didapat FES dengan jumlah channel yang banyak. Sistem sensor gait analysis digunakan untuk melihat perubahan sudut dan juga arah yang dihasilkan dari anggota tubuh yang digerakkan. Pada gerakan extension dan flexion pada sensi lutut (knee joint), sistem sensor akan membaca sudut yang dihasilkan. Selain itu, dengan adanya sistem kendali cycle-to-cycle control, maka hasil pembacaan sudut dari sensor akan digunakan sebagai input pada sistem kendali. Sudut yang tercapai akan dibandingkan dengan sudut referensi (reference angle) dan durasi stimulus akan diatur secara otomatis.

\section{METODE PENELITIAN}

\section{A. Perancangan Sistem}

Diagram blok untuk sistem FES ini dapat dilihat pada Gambar 1. Perancangan sistem dibagi menjadi 2 bagian, yaitu perancangan pada software dan hardware. Sistem pada hardware akan meliputi rangkaian electrical stimulator dan sensor system. Sedangkan pada perancangan software dibagi menjadi 2, yaitu embedded system dan user-interface. Pada saat akan dilakukan stimulasi pengguna akan memasukkan data input yang berupa besarnya tegangan input, durasi tiap cycle dan juga durasi pada driver channel yang berfungsi untuk menentukan lama stimulasi pada otot subyek pada user interface. Setelah stimulator berjalan, maka sensor akan membaca sudut yang dihasilkan oleh segmen knee joint

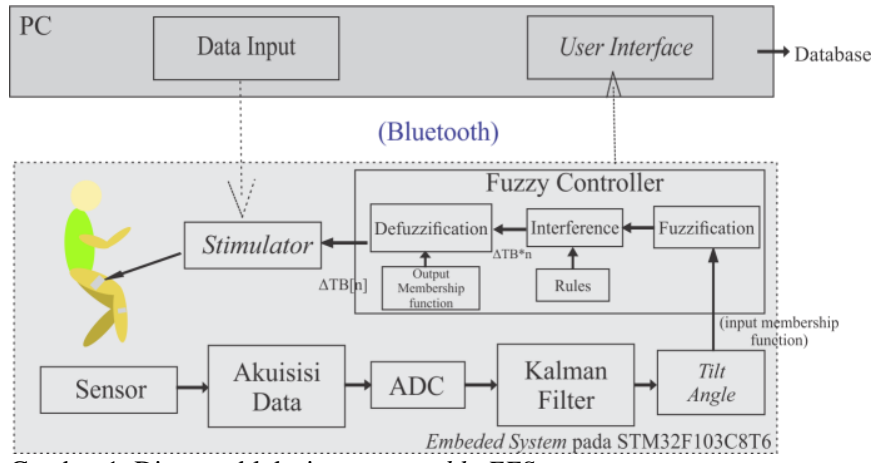


tersebut. Hasil pembacaan sensor akan diproses secara embedded pada mikrokontroler STM32F103C8T6. Hasil pembacaan sensor akan melalui proses pre-processing yang terdiri dari filter HPF dan filter kalman yang kemudian akan dijadikan sebagai feedback sistem cycle-to-cycle dengan menggunakan fuzzy controller. Dari hasil keluaran fuzzy akan dihasilkan nilai $\Delta \mathrm{TB}$ untuk mengatur durasi yang baru. Keseluruhan sistem ini akan dimonitor oleh user-interface program dan data hasil percobaan akan dimasukkan kedalam database dalam bentuk *txt.

\section{B. Perancangan Electrical Stimulator}

Diagram blok sistem electrical stimulator dapat dilihat pada Gambar 2. Rangkaian ini akan ditempatkan pada modul slave pada segmen shank. Pada rangkaian electrical stimulator, pulsa yang dikehendaki adalah sebagai berikut [3]:

- Pulsa monophasic

- Tegangan maksimum 100V

- Lebar pulsa $200 \mu \mathrm{S}$

- Frekuensi pulsa $20 \mathrm{~Hz}$

Dalam merealisasikan tegangan hingga $100 \mathrm{~V}$, dibutuhkan rangkaian non-isolated boost converter. Rangkaian ini akan ditempatkan dalam modul slave dan berukuran kecil dan ringkas. Prinsip kerja dari rangkaian boost converter didasari oleh mekanisme saklar. Saklar akan berfungsi untuk melakukan charge-discharge pada kapasitor dan induktor. Dalam perancangan, sebagai pengganti saklar, akan digunakan transistor SMD jenis MMBTA42 (NPN) untuk melakukan proses switching.

Setelah rangkaian dapat menghasilkan 100 Volt, langkah selanjutnya adalah membangkitkan pulsa dengan frekuensi 20 $\mathrm{Hz}$ dan lebar $200 \mu \mathrm{S}$. Rangkaian pembangkit ini menggunakan half $\mathrm{H}$-bridge yang dirancang dengan transistor PNP dan NPN. Pada bagian akhir rangkaian, keluaran hasil pembangkit tegangan ini akan dimasukkan kedalam rangkaian driver channel agar pada saat stimulasi, dapat ditentukan dimana channel yang digunakan.

\section{C.Perancangan Sistem Sensor}

Dalam upaya merealisasikan suatu sistem closed-loop, maka dibutuhkan sebuah feedback. Pada penelitian ini, nilai feedback yang digunakan adalah nilai pengukuran sudut pada knee joint yang menggunakan modul accelerometer dan gyrometer yang di tempatkan pada kedua modul master dan slave. Modul accelerometer yang digunakan adalah GY-61 yang dilengkapi oleh sensor MEMS tipe ADXL35, sedangkan gyroscope yang digunakan adalah ENC-03. Kedua sensor tersebut akan digabung menjadi satu untuk mendapatkan suatu sudut seperti pada Gambar 3.

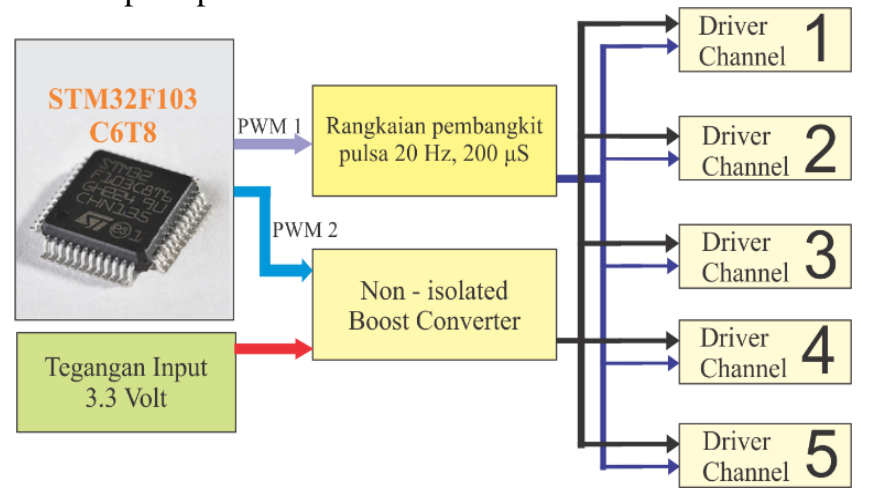

Gambar 2. Diagram blok sistem electrical stimulator
Accelerometer adalah sebuah alat yang dapat mengukur 3 derajat kebebasan (degree of freedom / DOF) yang berbeda. Ketiga DOF itu adalah poros x, y dan z. Pada ADXL35, skala penuh yang dapat terukur sebesar $3 \mathrm{~g}$, dimana $1 \mathrm{~g}$ adalah 9,81 $\mathrm{m} / \mathrm{detik}^{2}$. Untuk mendapatkan sudut pada satu titik, digunakan persamaan berikut yang telah diberikan oleh datasheet.

$$
V_{\text {out }}=V_{\text {off } f a t}+S * \sin \theta
$$

Sudut yang dicari dituliskan pada $\sin \theta$, sedangkan $\mathrm{S}$ adalah nilai sensitifitas dan $\mathrm{V}_{\text {offset }}$ adalah nilai tegangan yang keluar pada saat sumbu $0 \mathrm{~g}$.

Gyroscope adalah suatu alat ukur yang mampu mengukur kecepatan sudut dalam satuan $\% \mathrm{~s}(\mathrm{deg} / \mathrm{sec})$. Berbeda dengan accelerometer, sensor ini hanya dapat mengukur 1 sumbu. Percepatan angular maksimum yang dihasilkan oleh sensor ini sebesar 300. Untuk mendapatkan kecepatan sudut dan posisi sudut gyroscope, maka digunakan persamaan yang didapatkan dari datasheet pada persamaan 2 dan 3.

$$
\begin{gathered}
\theta_{n}=\theta_{n-1}+\omega_{n} \cdot d t \\
\omega_{n}=\frac{V_{\text {out }}-V_{\text {zero of fset }}}{S}
\end{gathered}
$$

Dari persamaan tersebut, akan didapatkan $\theta_{n n}$ sebagai posisi sudut yang diukur pada saat $-\mathrm{n}, \omega_{n n}$ merupakan kecepatan sudut gyroscope, dt adalah time sampling yang digunakan rangkaian, Voffset merupakan tegangan pada saat $0 \mathrm{~g}$, dan $\mathrm{S}$ adalah sensitivitas.

Agar didapatkan pengukuran yang benar-benar akurat dalam mengukur sudut persendian lutut (knee-joint), maka diperlukan penempatan posisi sensor pada segmen thigh dan shank. Pada modul master yang ditempatkan pada segmen thigh, digunakan accelerometer untuk sumbu $\mathrm{Z}$ dan $\mathrm{Y}$. Sedangkan untuk gyroscope sensor ditempatkan searah dengan sumbu Y. Namun, untuk modul slave, digunakan accelerometer untuk sumbu $\mathrm{Z}$ dan $\mathrm{X}$, dan untuk sumbu gyroscope digunakan sumbu X. Digunakan 2 sumbu pada sensor accelerometer dikarenakan pada saat percobaan pengukuran, penggunaan 1 sumbu akan menimbulkan pembacaan yang kurang akurat, maka dari itu, penggunaan 2 sumbu dimaksudkan untuk saling melengkapi dan saling menghilangkan nilai sudut yang tidak dapat terbaca oleh sumbu yang statu. Untuk mendapatkan sudut kemiringan dari kedua modul tersebut maka dapat dituliskan pada persamaan 4.

$$
\theta_{b_{t, t s}}=\operatorname{ArcTan}\left(\frac{A_{Z}}{A_{X}}\right)
$$
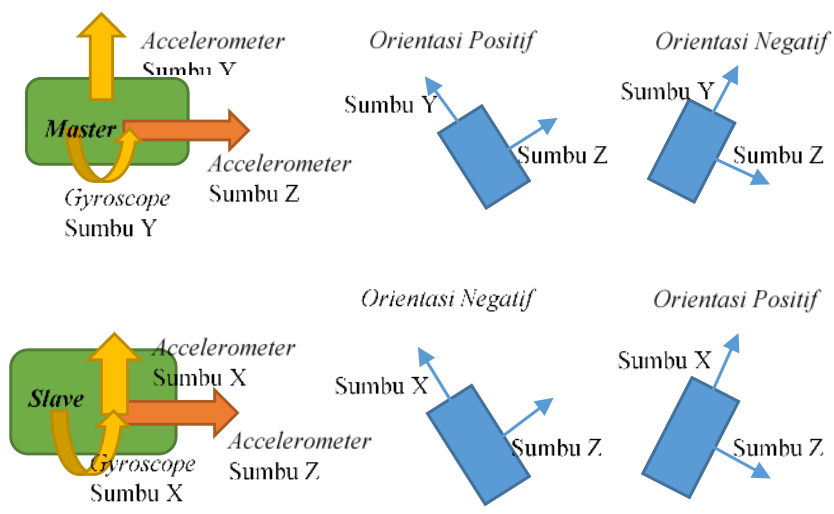

Gambar 3. Axis yang digunakan pada modul master (a) dan modul slave (b) 


\section{D.Perhitungan Knee Joint Angles Berdasarkan Sensor Fusion}

Setelah mendapatkan besaran sudut pada segmen thigh dan shank, maka diperlukan sebuah persamaan untuk menghitung kemiringan dari knee joint, sebagai gabungan dari kedua segmen. Setelah didapatkan sudut pada setiap segmen pada persamaan (6), hasil pembacaan yang dalam satuan radian perlu dikalikan dengan $\frac{180}{\pi}$. Hasil pada Sumbu X, Y dan Z adalah vektor akselerasi pada accelerometer dalam satuan $\mathrm{g}$. Berlandaskan persamaan sudut tilt dan sketsa free body diagram, maka persamaan untuk mendapatkan knee joint angle dapat dihitung dengan persamaan:

$$
\theta_{k}=\theta_{\mathrm{t}}-\theta_{g}
$$

Setelah mendapatkan nilai sudut tilt dalam sistem FES dengan baik maka dibutuhkan sebuah metode preprocessing. Dikarenakan sudut yang didapatkan cukup rentan terhadap noise atau gangguan dikarenakan sensitivitas dari sensorsensor tersebut. Oleh karena itu diperlukan sebuah filter untuk menghilangkan gangguan-gangguan tersebut. Selain itu, karena sifat sensor - sensor yang terlalu sensitif, diperlukan sebuah metode untuk meminimalisir kesensitifitasan dari sensor accelerometer dan gyroscope. Metode tersebut disebut juga sebagai Kalman Filter.

Dalam proses ini, digunakan low pass filter $2^{\text {nd }}$ order yang akan meredam noise dari keluaran sensor. Proses ini akan menggunakan filter dengan frekuensi cutoff $4 \mathrm{~Hz}$, Setelah mendapatkan nilai yang telah difilter, maka hasil tersebut akan diproses didalam kalman filter, untuk mengestimasi nilai sudut yang akan dihasilkan. Filter ini dapat menggabungkan nilai gyroscope yang mengukur sudut tilt secara dinamis dan presisi namun cenderung melayang, dan nilai accelerometer yang kurang stabil dalam keadaan dinamis namun tidak ada kecenderungan untuk melayang. Prinsip dari filter ini adalah predict atau mengestimasi dan correct atau mengoreksi. Pada fase predict, sudut yang dihitung merupakan sudut dari gyroscope yang diintegralkan terhadap waktu, sedangkan pada fase correct merupakan perbaikan nilai drift dari hasil gyroscope.

\section{E. Fuzzy Controller untuk Kendali Cycle-to-cycle Control}

Sebelum melakukan pembahasan pada fuzzy controller, maka akan dilakukan pembahasan terlebih dahulu tentang cycle-to-cycle control. Dengan menggunakan cycle-to-cycle control, setiap otot akan di stimulasi oleh sebuah rentetan stimulus yang berada didalam satu durasi. Stimulus yang dihasilkan akan memiliki amplitudo, frekuensi dan lebar pulsa yang sama untuk membuat target otot bergerak seperti yang diinginkan. Sistem kendali ini akan dapat menghasilkan lama durasi (burst duration) dari sinyal stimulus yang akan ditentukan dari penggunaan fuzzy controller. Persamaan untuk cycle-to-cycle control dituliskan pada persamaan 6. Nilai $T B_{[n-1]}$ adalah durasi dari pulsa stimulus yang diberikan pada siklus sebelumnya, nilai $\Delta T B_{[n]}$ adalah nilai output kontroler, sedangkan nilai $\triangle T B$ akan didapatkan dari fuzzy controller.

$$
\Delta T B_{[n]}=T B_{[n-1]}-\Delta T B
$$

Sistem kendali fuzzy adalah sebuah metode pengaturan yang berdasarkan dengan logika ketidak pastian (fuzzy). Dalam kata lain, skema dari sistem kendali ini dapat di tuliskan dalam bentuk if - then. Sistem kontrol fuzzy memiliki 3 bagian penting, yang pertama adalah fuzzification. Pada proses ini, diberikan nilai - nilai dan derajat keanggotaan sebagai masukan. Input dalam hal ini adalah nilai error yang dihasilkan apabila dibutuhkan pergerakan knee flexion. Pada saat dibutuhkan gerakan knee extension sistem ini akan menggunakan nilai error dan nilai desired range (sudut yang diinginkan) sebagai nilai masukan. Nama lain dari skema ini adalah single-input-single-output (SISO) untuk knee flexion, dan multiple-input-multiple-output (MISO) untuk gerakan knee extension. Nilai sudut referensi pada kedua gerakan tentunya berbeda. Pada knee extension, sudut referensi yang digunakan adalah $15^{\circ}$ sedangkan pada knee flexion sebesar $69^{\circ}$. Semua sudut referensi diambil dari titik $0^{\circ}$ pada knee joint.

Seperti yang telah disebutkan, kedua sistem kendali ini menggunakan nilai error sebagai nilai masukan. Untuk mendapatkan nilai error digunakan pengurangan nilai sudut yang dituju dengan nilai sudut maksimum yang tercapai oleh subyek pada saat itu. Persamaan ini dapat dilihat pada persamaan 7 .

$$
\text { Error }=\theta_{\text {target }}-\theta_{\max }
$$

Sedangkan nilai desired range didapatkan dari hasil perbedaan dari sudut extension pada siklus saat ini, dibandingkan dengan sudut referensi pada kontak awal. Dengan kata lain, desired range adalah trayektori yang akan ditempuh oleh segmen yang akan distimulasi. Pada rancangan ini, $\theta_{\text {target }}$ yang digunakan untuk gerakan knee extension adalah $15^{\circ}$ sedankan untuk gerakan knee flexion adalah $69^{\circ}$. Dalam merancang kontroler fuzzy, maka variabel input pada "error" dan "desired range" dibedakan menjadi 7 istilah linguistik: negative large (NL), negative medium (NM), negative small (NS), zero $(\mathrm{Z})$, positive small $(\mathrm{PS})$, positive medium (PM) dan positive large (PL). Aturan pada sistem kendali fuzzy ini dapat dilihat pada Tabel 1 untuk sistem kendali MISO dan Tabel 2 untuk sistem kendali SISO.

Tabel 1.

Tabel fuzzy rule untuk kendali MISO

\begin{tabular}{cclll}
\hline \hline & & & \multicolumn{2}{c}{$\begin{array}{c}\text { Desired Range } \\
\text { M }\end{array}$} \\
\hline \multirow{4}{*}{ Error } & NL & PL & PL1 & PL2 \\
& NM & PM & PL2 & PL2 \\
& NS & PS & PM & PL1 \\
& Z & Z & Z & Z \\
& PS & NS & NM & NL \\
& PM & NM & NL & NL1 \\
& PL & NL & NL1 & NL2 \\
\hline \hline
\end{tabular}

Tabel 2.

Tabel fuzzy rule untuk kendali SISO

\begin{tabular}{llllllll}
\hline \hline Error & NL & NM & NS & Z & PS & PM & PL \\
\hline$\Delta$ TB & PL & PM & PS & Z & NS & NM & NL \\
\hline \hline
\end{tabular}


Tabel 3.

Nilai sudut yang digunakan untuk nilai error pada MISO

\begin{tabular}{cccc}
\hline \hline Keterangan & Nilai Minimum & Nilai Puncak & $\begin{array}{c}\text { Nilai } \\
\text { Maksimum }\end{array}$ \\
\hline NL & -15 & -12 & -9.5 \\
NM & -10.5 & -8 & -5.5 \\
NS & -6.5 & -4 & -1.5 \\
Z & -2.5 & 0 & 2.5 \\
PS & 1.5 & 4 & 6.5 \\
PM & 5.5 & 8 & 10.5 \\
PL & 9.5 & 12 & 15 \\
\hline \hline
\end{tabular}

Tabel 4.

Nilai sudut yang digunakan untuk nilai desired range pada MISO

\begin{tabular}{cccc}
\hline \hline Keterangan & Nilai Minimum & Nilai Puncak & $\begin{array}{c}\text { Nilai } \\
\text { Maksimum }\end{array}$ \\
\hline NL & -15.1 & -11.5 & -9.5 \\
NM & -10 & -7.5 & -5 \\
NS & -5.5 & -3 & -0.5 \\
Z & -1 & 0 & 1 \\
PS & 0.5 & 1.5 & 2.5 \\
PM & 2 & 3 & 4 \\
PL & 3.5 & 4.5 & 4.9 \\
\hline \hline
\end{tabular}

Cara pembacaan dari tabel 1 dan 2 dapat menggunakan analogi if - then. Misalkan input pada error yang dihasilkan berada pada kisaran PS (positive small), dan input pada desired range berada pada kisaran medium. Maka hasil output, yaitu nilai $\Delta T b$ yang dihasilkan berada pada NM (negative medium). Dalam implementasinya, kedua sistem kendali ini menggunakan nilai sudut yang tertera dalam kondisi-kondisi yang telah ditetapkan. Nilai sudut yang digunakan untuk sistem kendali MISO dapat dilihat pada Tabel 3 dan Tabel 4. Sedangkan, untuk sistem kendali SISO, besaran yang digunakan dalam penentuan nilai error dapat dilihat pada Tabel 5 .

Tabel 5.

Nilai sudut yang digunakan untuk nilai error pada SISO

\begin{tabular}{cccc}
\hline \hline Keterangan & Nilai Minimum & Nilai Puncak & $\begin{array}{c}\text { Nilai } \\
\text { Maksimum }\end{array}$ \\
\hline NL & -81 & -35 & -25 \\
NM & -27.5 & -17.5 & -7.5 \\
NS & -10 & -5 & 0 \\
Z & -2.5 & 0 & 2.5 \\
PS & 0 & 5 & 10 \\
PM & 7.5 & 17.5 & 27.5 \\
PL & 25 & 35 & 69 \\
\hline \hline
\end{tabular}

Tabel 6.

Nilai sudut yang digunakan untuk nilai $\Delta \mathrm{TB}$

\begin{tabular}{cccc}
\hline \hline Keterangan & Nilai Minimum & Nilai Puncak & $\begin{array}{c}\text { Nilai } \\
\text { Maksimum }\end{array}$ \\
\hline NL & -350 & -300 & -225 \\
NM & -275 & -200 & -125 \\
NS & -175 & -100 & -25 \\
Z & -75 & 0 & 75 \\
PS & 25 & 100 & 175 \\
PM & 125 & 200 & 275 \\
PL & 225 & 300 & 350 \\
\hline \hline
\end{tabular}

Setelah mendapatkan kisaran dimana $\Delta T b$ akan didapatkan, maka diperlukan sebuah metode defuzzification untuk merubah nilai hasil fuzzification yaitu bilangan fuzzy menjadi nilai pasti atau disebut crisp set. Pada perencanaan, metode defuzzification yang digunakan adalah metode Centroid. Setelah mendapatkan nilai $\triangle T B$, maka hasil tersebut akan ditambahkan pada burst duration (lama durasi) stimulasi pada otot pasien.

\section{HASIL PENGUJIAN DAN ANALISA}

\section{A. Uji Coba Rangkaian Electrical Stimulator dan Sensor}

Langkah pertama, dilakukan ujicoba pada rangkaian nonisolated boost converter untuk melihat tegangan output yang dihasilkan. Percobaan ini dilakukan dengan merubah nilai frekuensi setiap $1 \mathrm{KHz}$ dari $9 \mathrm{KHz}$ hingga $22 \mathrm{KHz}$ dengan nilai dutycycle yang bervariasi. Hasil keluaran nilai boost converter dapat dilihat pada Gambar 4. Gambar tersebut merupakan grafik hasil keluaran boost converter pada frekuensi yang berbeda. Dari hasil yang didapatkan, setiap frekuensi yang digunakan akan menghasilkan tegangan yang berbeda-beda. Selain nilai tegangan yang berbeda, terdapat juga beberapa tegangan yang menurun ketika duty cycle digunakan dalam nilai tertentu. Maka diputuskan untuk menggunakan frekuensi $20 \mathrm{KHz}$ untuk rangkaian boost converter. Tegangan maksimum yang dihasilkan pada saat digunakan frekuensi ini sebesar dan tegangan maksimum yang dapat dikeluarkan oleh rangkaian ini sebesar 98.01 Volt.

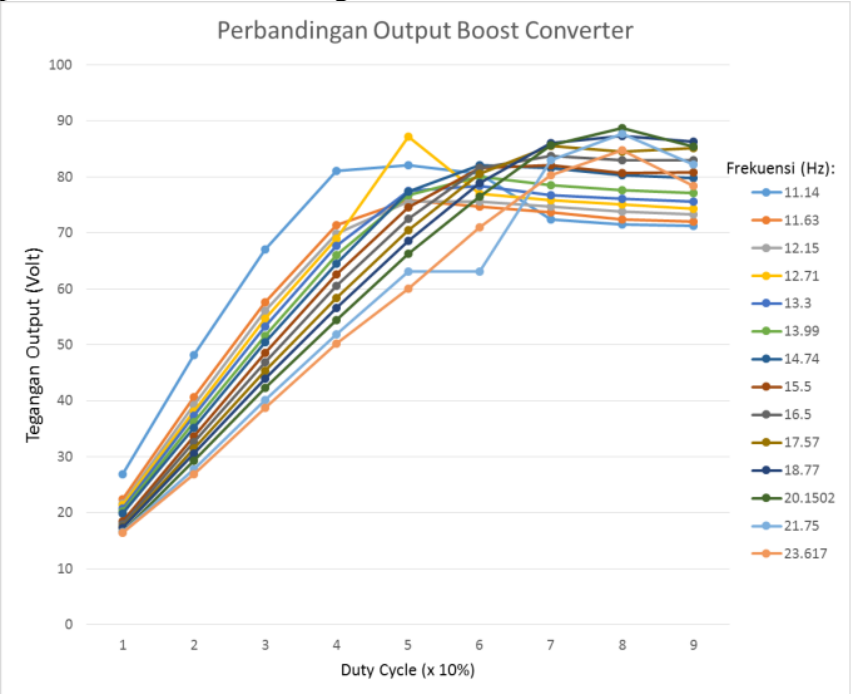

Gambar 4. Perbandingan tegangan output boost converter terhadap duty cycle dan frekuensi

Setelah dilakukan ujicoba pada rangkaian boost converter, maka dilakukan ujicoba pada rangkaian pembangkit sinyal 200 $\mu \mathrm{S}, 20 \mathrm{~Hz}, 100 \mathrm{~V}$. Uji coba ini menggunakan oscilloscope untuk melihat hasil lebar pulsa dan frekuensi yang dihasilkan oleh rangkaian apabila tidak diberikan beban seperti pada Gambar 5. Pulsa yang dihasilkan merupakan hasil keluaran pada mikrokontroler pada PWM2. Tegangan maksimum hasil rangkaian ini hanya dapat mencapai 98 Volt, namun hal tersebut tidak menjadi masalah karena hasil keluaran sudah mendekati rancangan yang diinginkan dan dengan tegangan 
sebesar 98 Volt, diyakini sudah dapat menggerakan otot subyek.
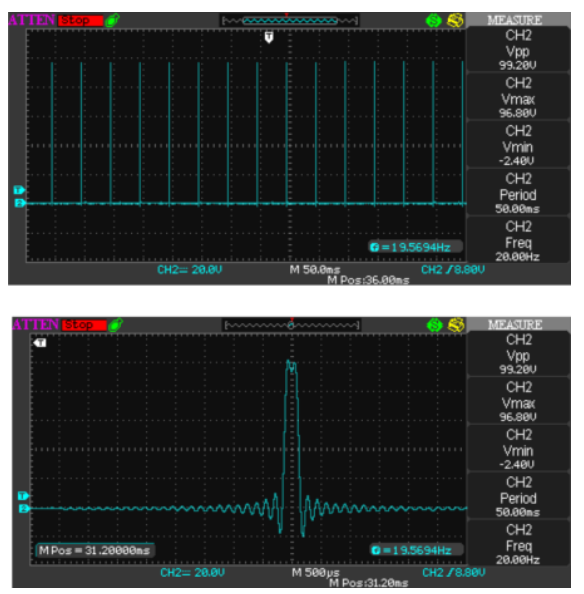

Gambar 5. Perbandingan tegangan output boost converter terhadap duty cycle dan frekuensi

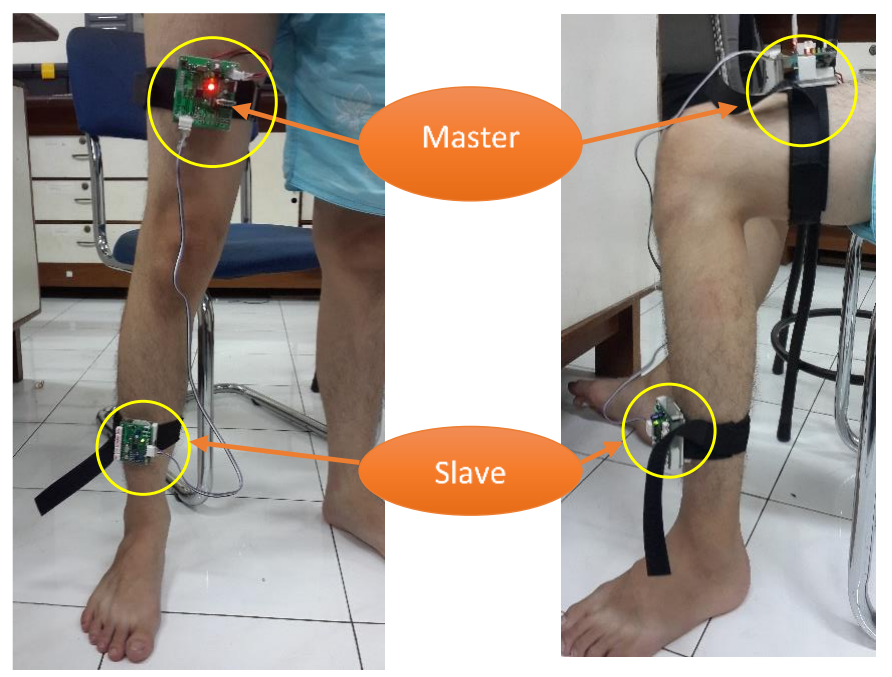

Gambar 6. Peletakkan modul master dan slave pada subyek kondisi berdiri dan duduk

Pada pengujian sensor, kedua modul ditempatkan pada thigh dan shank seperti pada Gambar 6. Rangkaian yang digunakan ada 2, yaitu rangkaian Master yang di letakkan pada segmen thigh dan rangkaian Slave yang ditempatkan pada segmen shank. Untuk mengetahui keakuratan dari pembacaan sensor, maka digunakan digunakan model kaki statis dengan perbandingan 1:1 dengan kaki manusia dan dilakukan pengukuran pada setiap sudutnya. Pengukuran sudut dengan model kaki ini dimulai dari sudut $-10^{\circ}$ hingga sudut $90^{\circ}$ yang menggambarkan pergerakkan ketika kaki bergerak flexion yaitu pada saat $90^{\circ}$ dan pergerakan extension yaitu pada saat $10^{\circ}$. Sudut yang terukur sudah menunjukan hasil yang baik dan perbedaan hasil pengukuran dengan hasil yang sebenarnya dibandingkkan dengan metode Real Mean Square Error (RMSE). Hasil yang didapatkan adalah $0.714^{\circ}$. Hasil ini merupakan hasil yang baik, dan dapat digunakan sebagai nilai feedback sistem FES.

\section{B. Uji Coba Kontroler}

Seperti yang diketahui, hasil keluaran dari kontroler ini adalah nilai $\Delta \mathrm{TB}$, yang didapatkan dari kontroler SISO dan kontroler MISO. Kedua pengujian ini menggunakan kaki statis sebagai penggerak, dan nilai setiap hasil pengukurannya dicatat dan digambarkan dalam grafik. Pada pengujian sistem kontrol SISO, nilai yang digunakan sebagai input adalah nilai error dari pengurangan sudut referensi dan sudut tercapai. Kaki statis digerakkan dari sudut $-10^{\circ}$ hingga sudut $90^{\circ}$. Sistem kontrol akan menghitung derajat keanggotaan dan akan menentukan nilai $\Delta \mathrm{TB}$ pada setiap cycle. Grafik hasil percobaan ini dapat dilihat pada Gambar 7. Pada gambar dapat terlihat dengan jelas bahwa nilai error akan berbanding terbalik dengan nilai achieved angle yaitu sudut yang tercapai. Dari hasil nilai error tersebut, dapat terlihat juga bahwa nilai $\triangle \mathrm{TB}$ akan menurun ketika nilai error menurun.

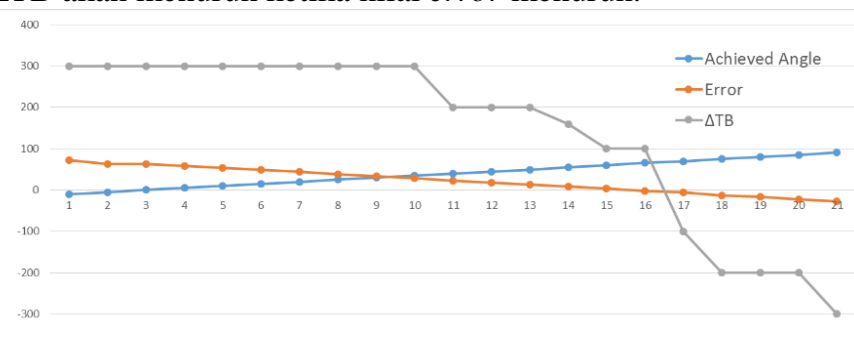

Gambar 7. Perbadingan nilai error, $\Delta \mathrm{TB}$ dan sudut yang tercapai pada kontroler SISO

Pada pengujian kontroler MISO, sesuai namanya maka nilai input yang digunakan adalah nilai error dan nilai desired range. Nilai error yang digunakan pada kontroler ini menggunakan metode yang sama seperti kontroler SISO. Sedangkan nilai desired range dapat diartikan sebagai trayektori yang akan ditempuh oleh segmen ketika akan distimulus. Sama seperti kontroler SISO, hasil keluaran dari sistem kontrol ini adalah nilai $\Delta \mathrm{TB}$. Hasil nilai $\Delta \mathrm{TB}$ adalah nilai durasi yang akan ditambahkan pada durasi stimulator. Jadi, semakin besar nilai $\Delta \mathrm{TB}$, semakin besar pula perubahan nilai durasi yang akan disalurkan pada subyek. Hal ini dapat terlihat dengan jelas pada grafik. Namun ketika durasi rangkaian sudah mencapai titik tertentu, yang pada percobaan ini ditentukan sebesar 5 detik, maka nilai durasi akan menjadi 0 dan akan ditambahkan kembail apabila nilai $\Delta \mathrm{TB}$ tetap sama. Nilai $\Delta$ TB digambarkan pada Gambar 8 sebagai bagian dari kontroler SISO.

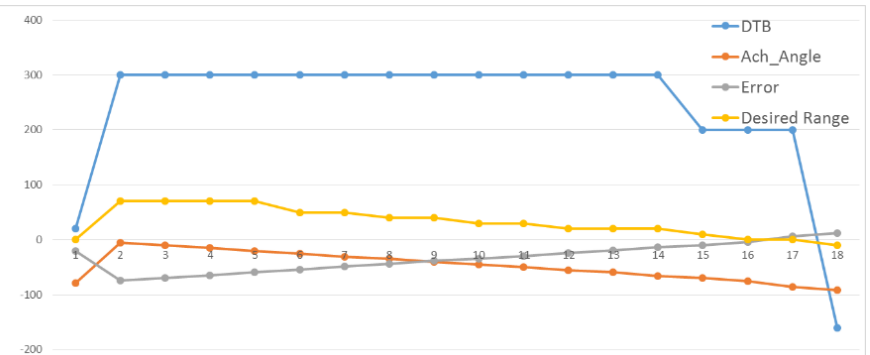

Gambar 8. Perbadingan nilai error, $\Delta \mathrm{TB}$ dan sudut yang tercapai pada kontroler SISO 


\section{Uji Coba Subyek}

Setelah melewati percobaan kontroler, maka dapat dikatakan bahwa perangkat sudah siap diujikan kepada subyek. Uji coba dilakukan dengan menempatkan elektroda pada lokasi otot biceps femoris long head (BFLH) yang berada pada kaki bagian posterior, seperti pada Gambar 9. Data yang diambil pada saat melakukan proses uji coba respon stimulator ini adalah stimulus minimum yang akan dirasakan subyek sesaat sebelum segmen subyek dapat bergerak, dan stimulus maksimum yang akan dirasakan subyek pada saat subyek melakukan knee flexion maksimum.

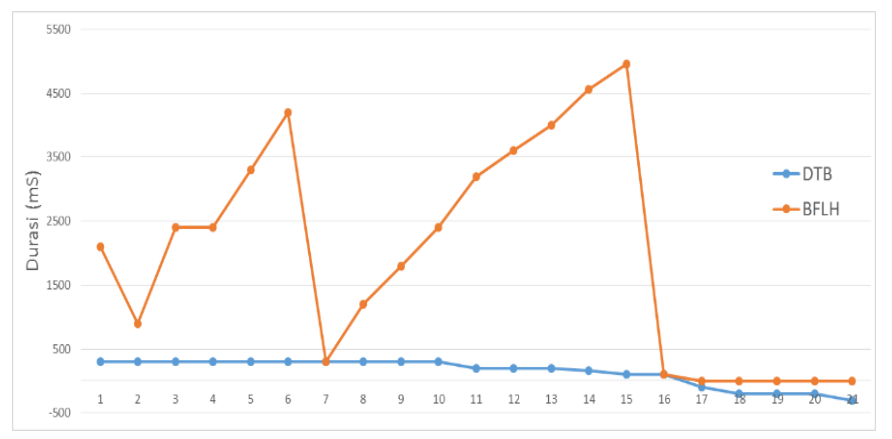

Gambar 9. Grafik perbandingan nilai $\Delta \mathrm{TB}$ dengan durasi burst duration pada pin BFLH

Tabel 7.

Perbandingan respon stimulus pada subyek

\begin{tabular}{|c|c|c|c|}
\hline Subyek & $\begin{array}{c}\text { Berat } \\
\text { Badan }\end{array}$ & $\begin{array}{c}\text { Stimulus } \\
\text { Minimum }\end{array}$ & $\begin{array}{c}\text { Stimulus } \\
\text { Maximum }\end{array}$ \\
\hline A & 80 & 51 & 60 \\
\hline B & 60 & 35 & 50 \\
\hline C & 83 & 60 & 90 \\
\hline
\end{tabular}

Hasil yang didapatkan adalah bahwa respon setiap subyek berbeda-beda. Dari ketiga subyek yang digunakan, dapat terlihat bahwa bentuk segmen thigh mempengaruhi peletakan elektroda, dimana letak otot BFLH juga mengikuti bentuk segmen thigh setiap orang. Selain itu, berat badan juga mempengaruhi hasil respon. Subyek yang memiliki berat badan yang lebih berat membutuhkan stimulus yang lebih besar dibandingkan subyek dengan berat badan ringan. Hasil percobaan dapat dilihat pada Tabel. Subyek A dan C memiliki berat badan yang cukup tinggi. Selain itu, bentuk segmen thigh yang dimiliki kedua subyek juga lebih lebar dibandingkan dengan subyek B. Dari hasil percobaan ini dapat disimpulkan bahwa subyek dengan berat yang cukup tinggi membutuhkan stimulus yang lebih besar.

\section{KESIMPULAN DAN SARAN}

Sistem kontrol cycle-to-cycle dengan fuzzy rule system terbukti cukup handal. Hasil yang dikeluarkan oleh $\triangle T b$ sesuai dengan hasil masukan yang berupa error dan desired range pada model kaki statis. Namun, untuk mendapatkan hasil yang baik pada subyek, peletakan elektroda pada otot kaki sangat berpengaruh pada hasil. Posisi otot pada setiap subyek akan berbeda, maka dari itu diperlukan keahilan untuk mencari lokasi otot yang akan digunakan. Hasil error yang dihasilkan dari sistem ini terbukti memiliki nilai yang cenderung kecil, dan sudut yang tercapai sudah mendekati sudut referensi yang digunakan. Respon stimulasi yang dihasilkan oleh subyek bergantung dari fisiologi subyek dan juga berat badannya. Semakin berat subyek, maka tegangan yang digunakan juga lebih besar daripada subyek yang memiliki berat lebih ringan.

\section{UCAPAN TERIMA KASIH}

Penulis mengucapkan rasa syukur kepada Tuhan YME karena atas rahmatNya dan penyertaanNya, penulis dapat menyelesaikan penelitian ini. Terimakasih juga kepada kedua orang tua penulis atas bantuan materil dan moril. Ucapan terimakasih kepada bapak dosen pembimbing, kakak kelas dan teman - teman seperjuangan yang telah memberikan fasilitas kepada penulis dan mendukung dalam menyelesaikan penelitian ini.

\section{DAFTAR PUSTAKA}

[1] Barbara M. Doucet, Amy Lam, dan Lisa Griffin. "Neuromuscular Electrical Stimulation for Skeletal Muscle Function". Yale J Biol Med. 2012; 85(2): $201-215$. [NCBI]

[2] Cheryl L. Lynch, G.M. Graham, dan M. R. Popovic. "Including non ideal Behaviour in Simulations of Functional Electrical Stimulation Applications". Artificial organs, 35(3): 267 - 269, 2011. [Individual.utoronto.ca]

[3] Arifin, A., T. Watanabe dan T. Masuko. "Application of Knowledge Engineering and Fuzzy System in Realizing Cycle - to - Cycle Control Method for Swing Phase of FES - induced Gait". International Symposium on Medical, Bio - and Nano - Electronics, $3^{\text {rd }}$ Edition 2008, pp.43-51. 